\title{
Cold Crucible Induction Melter Test for Crystalline Ceramic Waste Form Fabrication: A Feasibility Assessment
}

\author{
Jake W. Amoroso ${ }^{\mathrm{a}}$ \\ James Marra ${ }^{\mathrm{a}}$ \\ Christopher S. Dandeneau ${ }^{a}$ \\ Kyle Brinkman ${ }^{\mathrm{b}}$ \\ Yun $\mathrm{Xu}^{\mathrm{b}}$ \\ Ming Tang ${ }^{\mathrm{c}}$ \\ Vince Maio $^{\mathrm{d}}$ \\ Samuel M. Webb ${ }^{\mathrm{e}}$ \\ Wilson K. S. Chiu ${ }^{\mathrm{f}}$ \\ asavannah River National Laboratory, Aiken, SC 29808, USA \\ ${ }^{\mathrm{b}}$ Clemson University, Clemson, SC 29634, USA \\ 'Los Alamos National Laboratory, Los Alamos, NM 87545, USA \\ dIdaho National Laboratory, Idaho Falls, ID 83415, USA \\ ${ }^{\text {e}}$ Stanford Synchrotron Radiation Lightsource, SLAC National Accelerator Laboratory, Menlo Park, CA \\ 94086, USA \\ ${ }^{\mathrm{f}}$ University of Connecticut, Storrs, Connecticut 06269-3139, USA
}

\section{ACKNOWLEDGEMENTS}

The authors gratefully acknowledge financial support from the DOE-NE Materials Recovery and Waste Form Development program, including programmatic support from James Bresee, Kimberly Gray, Terry Todd and John Vienna. The authors are grateful for the support of Nuclear Energy University Program of the US Department of Energy Award ID: DE-NE0008260, CFA-14-6357: "A New Paradigm for Understanding Multiphase Ceramic Waste Form Performance." Portions of this research were carried out at the Stanford Synchrotron Radiation Lightsource, a national user facility operated by Stanford University on behalf of the U.S. Department of Energy, Office of Basic Energy Sciences. The authors also thank Phyllis Workman, Katie Hill, and David Missimer at Savannah River National Laboratory for assistance with sample preparation and property measurements, and Tommy Edwards at Savannah River National Laboratory for statistical analysis of composition data. Use of the Stanford Synchrotron Radiation Lightsource, SLAC National Accelerator Laboratory, is supported by the U.S. Department of Energy, Office of Science, Office of Basic Energy Sciences under Contract No. DE-AC02-76SF00515.

\section{Abstract}

The first scaled proof-of-principle cold crucible induction melter (CCIM) test to process a multiphase ceramic waste form from a simulated combined $(\mathrm{Cs} / \mathrm{Sr}$, lanthanide and transition metal fission products) commercial used nuclear fuel waste stream was recently conducted in the United States. X-ray diffraction, 2-D X-ray absorption near edge structure (XANES), electron microscopy, inductively coupled plasma-atomic emission spectroscopy (and inductively coupled plasma-mass spectroscopy for Cs), and product consistency tests were used to characterize the fabricated CCIM material. Characterization analyses confirmed that a crystalline ceramic with a desirable phase assemblage was produced from a melt using a CCIM. Primary hollandite, pyrochlore/zirconolite, and perovskite phases were identified in addition to minor phases rich in $\mathrm{Fe}$, $\mathrm{Al}$, or $\mathrm{Cs}$. The material produced in the CCIM was chemically homogeneous and displayed a uniform phase assemblage with acceptable aqueous chemical durability. 


\section{INTRODUCTION}

Several countries are (or have in the past) reprocessing commercial used nuclear fuel (UNF), including France, Great Britain, Germany, and Japan. The associated nuclear waste is commonly immobilized in borosilicate glasses because these materials have demonstrated the capacity to accommodate a wide range of fission products and the technologies employed for processing glass are well developed. The United States continues to evaluate commercial fuel reprocessing through research conducted under the DOE-NE Fuel Cycle Technologies Program. As part of the DOE-NE Fuel Cycle Technologies Program, alternative waste forms are being investigated for the purpose of immobilizing projected waste streams generated from future reprocessing of commercial UNF. The primary waste forms of interest are glass-ceramic composites and ceramics. The former allows for the incorporation of fission products with limited solubility in borosilicate glass by intentional crystallization into chemically durable phases such as oxyapatite, powellite, lanthanide-borosilicate, and cerianite.(1-2) The principal advantage of ceramic waste forms is that waste ions are incorporated (high-level waste loadings vary from 10-35 wt\%) into durable mineral phases, which are considerably less soluble in water relative to vitreous silicates, especially above atmospheric temperatures and pressures. High temperatures and pressures may be of concern because natural intrusive water will eventually enter the waste storage and disposal area over long time periods. In such a scenario, the decay heat of the waste form builds natural convective flow currents for the intrusive water. This heated water, after leaching from the given waste form, flows away, cools, precipitates the leached material, and then is recirculated back to the waste form, thereby restarting the leaching cycle. Testing of this (type) indicates that Synroc phases, like their natural analogues, are resistant to these hydrothermal leaching conditions. Many standard durability tests do not take into account such thermal conditions but, when considered, non-crystalline waste forms (including glass) are not as durable under hydrothermal conditions.(3-6)

The most widely studied ceramic waste forms are derived from Synroc (i.e., synthetic rock) materials developed in Australia in the late 70's.(7) Synroc-type phases are composed of geochemically stable titanate minerals and are attractive for high-level waste (HLW) immobilization due to their ability to incorporate nearly all elements present in HLW, including fission products and minor actinides, in a crystalline lattice. The stability of synroc, and similar man-made analogs that mimic naturally occurring minerals, is substantiated by geological specimens containing uranium, thorium, and other naturally occurring radioactive isotopes recovered from the earth's crust after millions of years in the natural environment.

Ceramic formulations are generally developed to target Ba-hollandite ( $\left.\mathrm{BaAl}_{2} \mathrm{Ti}_{6} \mathrm{O}_{16}\right)$, zirconolite $\left(\mathrm{CaZrTi}_{2} \mathrm{O}_{7}\right)$, and perovskite $\left(\mathrm{CaTiO}_{3}\right)$, which are the characteristic titanate minerals comprising synroc. Elements with a $3+$ or $2+$ valance form perovskite- $\left(\left(\mathrm{A}^{+2}\right) \mathrm{TiO}_{3}\right)$ and pyrochlore $\left(\left(\mathrm{A}^{+3}\right)_{2} \mathrm{Ti}_{2} \mathrm{O}_{7}\right)$-type phases (8-9), while zirconium (4+ valence) partitions to a zirconolite $\left(\mathrm{CaZrTi}_{2} \mathrm{O}_{7}\right)$ phase (10). Cs and $\mathrm{Rb}$ elements partition to a hollandite structure based on the general formula $\mathrm{Ba}_{x} \mathrm{Cs}_{y} \mathrm{M}_{z} \mathrm{Ti}^{+4}{ }_{8-z} \mathrm{O}_{16}$, where $z=$ $2 x+y$ for trivalent cations and $z=x+y / 2$ for divalent cations in order to maintain charge neutrality (11-13). Zirconolite and pyrochlore are the major immobilization hosts for actinides, such as $\mathrm{Pu}$, and the rare earth elements (i.e., Sc, Y, and the lanthanides), whereas perovskite is the principal immobilization host for Sr. Ba-hollandite is primarily used to immobilize $\mathrm{Cs}, \mathrm{K}, \mathrm{Rb}$, and $\mathrm{Ba}$. Depending on the waste composition, other minor synthetic Synroc mineral phases can be included, such as other forms of hollandite, magnetoplumbite (also for $\mathrm{Sr}$ ), pyrochlore, and rutile $\left(\mathrm{TiO}_{2}\right) .(3)$

Synroc materials are typically processed using some type of solid-state reaction, most notably hot isostatic pressing (HIP), which has been extensively developed by the Australian Nuclear Science and Technology Organization (ANSTO). However, this type of bulk ceramic processing in radioactive environments can be complex and has limited the use of ceramics for waste immobilization. As an alternative, synroc-type materials can be fabricated through a melt process, where crystallization and 
solidification occur upon cooling from the melt temperature.(14-16) In this manner, the bulk processing of ceramic forms would be simplified, and the advantages of a crystalline ceramic waste form can be combined with both existing processing flowsheets and knowledge currently implemented in waste vitrification processes.

Savannah River National Laboratory (SRNL) is developing a melt-process to convert waste generated from UNF reprocessing into a durable ceramic waste form as part of the United States DOE-NE Fuel Cycle Technologies Program.(17) The waste form is designed to crystallize into an engineered multiphase synroc-type ceramic upon cooling from a melt (melt processing). However, the relatively high melting temperatures $\left(>1500^{\circ} \mathrm{C}\right.$ ) of synroc-type ceramics (as well as glass-ceramics) limits the number of practical melter designs and excludes the use of traditional joule heated melters (JHMs). The Cold Crucible Induction Melter (CCIM) is an obvious melter choice as it is a demonstrated technology for processing radioactive waste (Russia, France, and South Korea) and can achieve the temperatures required to melt ceramic synroc materials.(18-19) Recently, a first-of-its-kind CCIM test in the United States was conducted at the Idaho National Laboratory (INL) to demonstrate proof-of-principle meltprocessing of multi-phase ceramic waste forms. The CCIM test was used to 1) produce a ceramic waste form via a scaled but representative process, 2) evaluate the material produced, and 3) assess the feasibility of the CCIM technology. The present work describes recent advances towards demonstrating a viable melt-processing technology for the fabrication of ceramic waste forms from UNF reprocessing.

\section{CCIM TEST SUMMARY}

In October of 2014, INL personnel melted and attempted to pour a ceramic using a CCIM. Approximately $30 \mathrm{~kg}$ of a dry, stoichiometric mixture of oxide and carbonate reagents supplied by the MoSci Corporation was employed as the CCIM feed. Chemical analysis confirmed the composition of the feed material prior to use (Refer to Section 4.1.2). The targeted and measured elemental concentrations are listed in Table 1. For the prepared feed, the measured composition was within typical analytical uncertainty limits of the target composition.

A Ti initiator ring and approximately $13.5 \mathrm{~kg}$ of feed was packed into the crucible $(101 / 2 \mathrm{in}$. inside diameter) of the CCIM to a height of $\sim 6$ in. The Ti initiator ring was suspended off the floor of the crucible with alumina spacers after previous attempts without ring supports resulted in the Ti ring sinking to the bottom of the crucible below the main induction zone before the charge material coupled with the induction frequency. The initial charge was used for primary ignition of the melt. No forced agitation or mixing was used during the test. A melt, as indicated by an optical pyrometer reading of $>1700^{\circ} \mathrm{C}$ and direct coupling to the material, was achieved in approximately $3 \mathrm{~h}$, at which point additional feed was added at $5.5 \mathrm{~kg} / \mathrm{hr}$. The radio frequency (RF) generator of the CCIM was operating at its design power $(60 \mathrm{~kW})$ level to maintain the melt and thus, an attempt was made to drain the melter after approximately $40 \mathrm{~min}$ (220 min from initiation) and $3 \mathrm{~kg}$ of added feed. Nitrogen flow to cool the drain assembly was subsequently stopped and the drain heater was powered on. Less than $5 \mathrm{~min}$ after being turned on, the drain heater element shorted out. To counter the loss of heater power, the flow rate of cooling water to the drain assembly was decreased. This immediately led to a water leak in the cooling system, which in turn triggered automatic shutdown of the RF generator and termination of the CCIM test. Figure 1 shows images of the loading of the CCIM crucible and the melted material.

\footnotetext{
${ }^{\mathrm{a}}$ The experimental parameters and operating conditions during the CCIM test are presented in greater detail elsewhere. (See V. C. Maio, "Production of a Low Temperature SYNROC All Ceramic Surrogate High Level Waste Form in INL's Cold Crucible Induction Melter Pilot -Validation of Test Completion," U.S. Department of Energy Report INL/MIS-14-34012 (FCRD-SWF2015-00256), Idaho National Laboratory, Idaho Falls, ID (2014).)
} 
Cooling water supplied to the crucible stays created a temperature gradient across the melted material during cooling. The estimated cooling rate of material in the center of the crucible was $\sim 6 \mathrm{~K} / \mathrm{min}$ (averaged over $4 \mathrm{~h}$ ), and the material near the crucible wall could have realistically cooled at rates as high as 100's K/min. After cooling, seven core samples were taken from the solidified material and characterized.

\section{Core Samples}

\subsection{Experimental}

\subsubsection{Sample Preparation}

Seven 1-inch diameter core samples were drilled from the solidified material in the CCIM for analysis. Figure 2 and Table 2 show the core locations and depths, respectively. Because many of the cores cracked during drilling, the cores were re-assembled and held together with thermo-set epoxy prior to sectioning and characterization. A representative image of an as-received, re-assembled core is presented in Figure 3. Figure 4 shows scanning electron microscopy (SEM) images of a representative core (sample F) in which dense, columnar, and porous microstructures are evident along the core length. In general, identifying and sectioning samples that were either dense or columnar in appearance was straightforward. Here, dense core specimens were denoted as Zone 1, while columnar samples were labeled Zone 2. Accurate identification of the porous sections was more difficult because the transition from a columnar to porous morphology was less definitive. Therefore, samples that could conclusively be identified as porous were labeled as Zone 3, and a fourth set of samples consisting of Zone 2 and Zone 3 material, where a definitive distinction was difficult to identify, were labeled Zone 5.

\subsubsection{Chemical Composition}

Inductively Coupled Plasma-Atomic Emission Spectroscopy (ICP-AES) was used to measure the concentrations of all elements with the exception of Cs, which was measured by Inductively Coupled Plasma-Mass Spectroscopy (ICP-MS). Samples were prepared via sodium peroxide fusion (PF) and lithium metaborate fusion (LM) methods. Both digestion methods were utilized because high concentrations of $\mathrm{TiO}_{2}$ and $\mathrm{Cr}_{2} \mathrm{O}_{3}$ are difficult to fully dissolve with the LM fusion method (the preferred digestion protocol for low concentration analysis). Digested samples were analyzed in duplicate for each element of interest by ICP-AES for a total of 4 measurements per element. Cs analysis was measured in duplicate using the same PF digestion solutions used in ICP-AES. The instrumentation was re-calibrated between the duplicate analyses and standards were intermittently measured to ensure the performance of the ICP instruments over the course of the analyses.

\subsubsection{Fe RedOx}

$\mathrm{Fe}^{2+} / \mathrm{Fe}^{3+}$ and $\mathrm{Fe}^{2+} / \mathrm{Fe}$ (total) ratios were determined by an absorption method using a UV-Vis spectrometer. Samples were first dissolved in a sulfuric-hydrofluoric acid mixture containing ammonium vanadate to preserve the $\mathrm{Fe}^{2+}$ content. Boric acid was then added to destroy iron-fluoride complexes, and ferrozine was introduced to form ferrous-ferrozine complexes for the determination of $\mathrm{Fe}^{2+}$ content. Ascorbic acid was then added to reduce $\mathrm{Fe}^{3+}$ to $\mathrm{Fe}^{2+}$, and a second absorbance spectrum was acquired to determine the total Fe content.(20) In addition to UV-Vis-based valence state data, Synchrotron-based hard X-ray microprobe measurements of element distributions were conducted at beam line 2-3 at the Stanford Synchrotron Radiation Lightsource (SSRL). The incident energy was selected using a Si(111) double crystal monochromator, and calibrated by defining the first derivative peak of a reference Fe metal foil to be $7112.0 \mathrm{eV}$. The current in the storage ring contained $500 \mathrm{~mA}$ at $3.0 \mathrm{GeV}$. The fluorescence lines of interest were measured using a Vortex Si-drift detector (Hitachi) using Xspress3 pule processing electronics (Quantum Detectors). The incident X-ray beam was focused to a size of $2 \times 2$ microns using Rh 
coated Kirkpatrick-Baez mirrors (Xradia Inc.). The x-ray fluorescence (XRF) intensity was mapped by rastering the sample in the focused beam. The XRF maps were performed at several energies across the $\mathrm{Fe}$ K-edge to preferentially excite different Fe species and other elemental species. Internal variation within the sample was used to differentiate the composition of the sample, rather than looking for specific crystalline standards to reference to. This process was sufficient to mark oxidation state and along with the remaining elemental compositions, make inferences on total composition.

\subsubsection{Phase Identification and Microstructure}

Samples were characterized via X-ray diffraction (XRD, D8 Advance, Bruker AXS Inc., Madison, WI) to identify the resulting phase(s). Portions of each sample were initially ground in an automatic Spex mill for 4 min using an agate cup and media. The powders were subsequently hand ground with an agate mortar and pestle in alcohol and mounted to a glass slide using a collodion/amyl acetate solution. The XRD patterns were collected from $5-70^{\circ} 2 \theta$ with a $0.02^{\circ}$ step size and scan rate of $1 \mathrm{~s} / \mathrm{step}$. XRD patterns for refinement were collected from $10-70^{\circ} 2 \theta$ at a scan rate of $1 \%$ min (Rigaku D/Max 2100 Powder X-ray Diffractometer), and analyzed using the Jade Software package to estimate phase abundances.

SEM and Energy Dispersive Spectroscopy (EDS) measurements were performed with a Hitachi SU6600 instrument at the Advanced Materials Research Lab of Clemson University. EDS maps were collected for $\mathrm{Cs}, \mathrm{Ba}, \mathrm{Mo}, \mathrm{Zr}, \mathrm{Cr}, \mathrm{Al}, \mathrm{Fe}, \mathrm{Nd}, \mathrm{Ca}, \mathrm{La}, \mathrm{Ce}$, and $\mathrm{Ti}$. Complementary imaging and $\mathrm{EDS}$ analysis were carried out at SRNL with a Hitachi TM3000 SEM.

Transmission electron microscopy (TEM)/scanning transmission electron microscopy (STEM)/Energydispersive X-ray spectroscopy (EDX) was performed using a FEI Tecnai F30 electron microscope operated at $300 \mathrm{kV}$ at Los Alamos National Laboratory. Samples were first mechanically polished to a thickness of less than $10 \mu \mathrm{m}$, at which point a precision ion polishing system (PIPS) was employed to yield electron transparent (less than $200 \mathrm{~nm}$ in thickness) specimens. EDX spectra were used to identify the chemical composition of observed crystalline phases, while selected area electron diffraction (SAED) patterns and high resolution TEM observations were utilized to determine the crystalline nature and structure of the phases.

\subsubsection{Chemical Durability}

A crushed sample leach test (Product Consistency Test (PCT) Method-A) was performed in triplicate to assess aqueous chemical durability. ${ }^{\mathrm{b}}$ Also included in the experimental test matrix were Environmental Assessment (EA) benchmark glass,(21) the Approved Reference Material (ARM), the Low-activity Reference Material (LRM), and blanks from the sample cleaning batch. All standards were ground, washed, and prepared according to the standard PCT procedure.(22) Fifteen milliliters of water were added to $1.5 \mathrm{~g}$ of sample or standard in stainless steel vessels. The vessels were closed, sealed, and placed in an oven at $90 \pm 2{ }^{\circ} \mathrm{C}$; the samples were maintained at this temperature for 7 days. Once cooled, the resulting solutions were sampled (filtered and acidified), and analyzed. Samples of a multi-element, standard solution were also included as a check on the accuracy of the ICP-AES instrument used for these measurements. Based on the measured compositions, fractional elemental release from the samples was calculated using the equation

$$
F R=\frac{C_{i} \times V_{s}}{m_{s} \times f_{i}}
$$

\footnotetext{
$\mathrm{b}$ The PCT has been used in melt-processed ceramic development research as a convenient method to measure specific elemental releases and identify phases with low durability. At this time, the test is not being used to provide quantitative durability values.
} 
where $\mathrm{C}_{i}$ is the concentration of element " $i$ " (e.g., Cs) in solution $(\mathrm{g} / \mathrm{L}), V_{s}$ is the volume of leachant solution (L), $m_{s}$ is the mass (g) of sample, and $f_{i}$ is the fraction of element " $i$ " in the unleached sample (unitless). From Eq. (1), the fractional release $(F R)$ of element " $i$ " is obtained as a figure of merit for the release of each element. Such a methodology was used to facilitate a comparison of the relative release among the samples.

\subsection{Results \& Discussion}

\subsubsection{Chemical Composition}

Sample from each core was selected for chemical analysis and grouped according to microstructure (see Section 4.1.1 for morphology categorization details). For a suitable representation of the bulk material, one additional sample was measured that was not sectioned prior to analysis. In total, 29 samples taken from 4 different cores and from various $(\sim 7)$ microstructure regions (i.e. zones) were analyzed.

Table 3 lists the measured elemental concentrations in the bulk CCIM material, i.e., the sample not sectioned and analyzed by zone. With the exception of $\mathrm{Al}, \mathrm{Cs}, \mathrm{Mo}$, and Te, the results indicate that the CCIM material composition was, in general, comparable to the target composition. Although no $\mathrm{Al}$ was added to the CCIM feed material, $\mathrm{Al}_{2} \mathrm{O}_{3}$ is known to react with the composition. Consequently, it is suspected that the $\mathrm{Al}_{2} \mathrm{O}_{3}$ supports used to hold the Ti initiator ring in placed reacted with the ceramic mixture during CCIM processing, thereby contributing to a measured $\mathrm{Al}$ concentration in the melted material. Cs is a highly volatile species and previous experiments have generally shown that about $50 \%$ of the Cs is lost during heating. However, it appears that less Cs, about 32\%, was lost in this CCIM test. The difference in measured Cs retention may be accounted for by a cold cap (the CCIM was fed during production) and the reduced surface area to volume ratio in the CCIM compared to lab testing. Substantial amounts (>70\%) of Mo and Te were unaccounted for in the measured analysis.

Table 1 indicates the feed material could have been deficient in Cs and Mo by as much as $\sim 15 \%$ and $\sim 30 \%$, respectively. Therefore, the Cs and Mo retention would be greater than if calculated from Table 3 . Nevertheless, significant evaporation of $\mathrm{Mo}$, Te, and $\mathrm{Cs}$, is plausible considering the melting temperatures of $\mathrm{MoO}_{3}, \mathrm{TeO}_{2}$, and $\mathrm{Cs}_{2} \mathrm{CO}_{3}$ are all in the range of $700-800{ }^{\circ} \mathrm{C}$ and is $\sim 500{ }^{\circ} \mathrm{C}$ for $\mathrm{Cs}_{2} \mathrm{O}$. (23) Furthermore, significant sublimation of pure $\mathrm{MoO}_{3}$ and $\mathrm{TeO}_{2}$ above the melting temperature has been reported.(24-25) The physical characteristics (i.e. low melting point and high vapor pressures at elevated temperatures) likely account for the lower than expected concentrations of Te, Mo, and Cs in the CCIM material.

Chemical composition was also measured as a function of vertical (zone) and radial location in the melter. The measured elemental concentration for each zone is plotted in Figure 5. In general, chemical composition did not depend on the zone from which the material came, indicating that the CCIM material was relatively homogeneous. However, the data presented in Figure 5 show that Al and several lanthanide series elements exhibited a greater variation in their means compared to other elements. Analysis of variance (ANOVA) was used to test for statistically significant differences in the means of the elemental concentrations between zones. ANOVA identified significant differences (at the 5\% significance level) for $\mathrm{Ce}, \mathrm{La}, \mathrm{Nd}, \mathrm{Pr}, \mathrm{Sr}$, and $\mathrm{Te}^{\mathrm{e}}$. Specifically, the means for Ce, $\mathrm{La}$, and $\mathrm{Pr}$ were not

\footnotetext{
${ }^{c}$ In all cases, measured elemental concentrations were used as opposed to target concentrations.

${ }^{\mathrm{d}}$ Refer to reference in footnote a for a discussion of the initiator ring setup.

${ }^{\mathrm{e}}$ The ANOVA for Te indicated significant differences between zone 2 and 5 but, zone 1 and 3 were common. This result does not appear to support the composition trend in the core samples and is ultimately unknown. Analysis of additional and a larger data set would be needed to confirm and explain the result.
} 
significantly different between zones 1, 2, and 5, or between zones 3 and 5 (i.e. Zone 5 was common). Similarly, the means for $\mathrm{Nd}$ and $\mathrm{Sr}$ were not significantly different between zones 1, 2, and 5 or between zones 2, 3, and 5 (i.e. zone 2 and 5 were common). The ANOVA results indicated that lanthanide series elements concentrations were dependent on vertical location (zone). Indeed, when individual element mean concentrations are plotted as a function of zone, as shown in Figure 6, La, Ce, Pr, Nd, Eu, Y, and $\mathrm{Sr}$ concentrations are observed to increase with vertical height in the cores. The trend in the lanthanide series elements is accompanied by a decrease in concentration of $\mathrm{Al}$ with vertical height in the cores but, all the other constituent elements do not exhibit any recognizable trend as a function of zone. The variance in the $\mathrm{Al}$ concentration is unknown. However, the closed-end $\mathrm{Al}_{2} \mathrm{O}_{3}$ cylinders used to support the Ti initiator ring during processing were observed to significantly react with the feed material, as evidenced by considerable dissolution and dimensional changes in one of the $\mathrm{Al}_{2} \mathrm{O}_{3}$ supports found during core drilling. Although $\mathrm{Al}$ is typically a $3+$ cation, it's ionic size is relatively small and direct substitution for the larger $3+$ rare-earths cations would not be expected. However, one possible explanation can be considered if the bottom of the melt cooled first and initiated a crystallization front proceeding upwards and following the crystallization sequence reported previously in which hollandite crystallization precedes the others upon cooling.(26) This could in turn lead to a slightly higher percent of hollandite at the bottom of the CCIM (in agreement with Figure 9) and thus, a lower rare-earth element concentration in that region. Alternatively, it is possible that Al may form a phase(s) or induce reactions making the rare-earth containing phases less energetically favorable. In contrast to the ANOVA results for $\mathrm{Ce}, \mathrm{La}, \mathrm{Nd}, \mathrm{Pr}, \mathrm{Sr}, \mathrm{a}$ linear correlation between the Te composition and location in the core was not observed. The differences found in the Te means could be correlated to an unknown phenomenon

In practical terms, the ANOVA results, the subjectivity involved in differentiating distinct boundaries between zones (morphology transitions, in particular between zones 3 and 2, hence the use of zone 5), and the microscopy results (Section 4.2.2) indicate most rare-earth elements are likely distributed less uniformly than other elements. Nevertheless, the magnitude of those differences remains small; the variances in the elemental means shown in Figure 5 and Figure 6 are typically less than 0.5 wt $\%$.

Figure 7 Figure 6shows the measured mean elemental concentrations for different core samples. In contrast to Figure 5, the data in Figure 7 Figure 6are grouped according to radial position in the melter. In general, smaller standard errors (relative to the zone analysis) were observed across the cores with the exception of core $\mathrm{F}$, which exhibited the greatest variation. The variation in core $\mathrm{F}$ was greatest for many of the lanthanide series elements and may be related to zone 3 elemental partitioning. An additional statistical analysis revealed that the ANOVA results for zone grouping were not affected by the Core F zone 3 measurements, i.e., nothing that would bias previous conclusions was found. Given that Core $\mathrm{F}$ was located near the wall of the crucible, it is possible that cooling gradients and interactions with the cold wall of the melter influenced elemental partitioning. Overall, the chemical composition measurements were remarkably consistent. The results confirm that the CCIM produced a melt that was chemically homogenous both radially and vertically. Based on these results, canister to canister homogeneity would be expected to be good but would need to be confirmed over extended operations.

\subsubsection{Fe RedOx}

Reducing conditions are known to have positive effects on the final properties of Synroc-type ceramic materials.(27-28) Ti metal was added to the CCIM during initiation, and it was expected that some amount of reduction was possible. Fe redox was measured on one sample, Core D, to determine the extent of reduction in the CCIM material. As with the other analyses, Fe redox was measured for different zones (microstructures) within the core. The results, summarized in Table 4, reveal that the CCIM material was partially reduced $\left(\sim 20 \% \mathrm{Fe}^{2+}\right)$. 
The distribution of $\mathrm{Fe}$ species in ceramic waste forms has not yet been extensively studied. In this work, mapping of the Fe fluorescence was performed as five discrete energies through the Fe K-edge (7113, $7120,7122,7130$, and $7133 \mathrm{eV}$ ) which were believed to be most sensitive to the Fe oxidation states expected. These maps were combined and principal component analysis (PCA) was performed to determine the spatial regions that showed the greatest chemical variation. Several X-ray absorption near edge spectra (XANES) were measured to confirm the chemical variation of Fe. From this analysis, three major components, two oxidized $\mathrm{Fe}$ and one reduced $\mathrm{Fe}$, were found, with oxidation state assignments based on edge position as shown in Figure 8 (spots 15 and 7). The intensities of the spectra were used as endmembers to perform linear combination fitting at each point of the multi-energy maps. The sum of the two oxidized species was used as the $\mathrm{Fe}^{3+}$ concentration in the sample. Procedures regarding PCA identification from image data (29-30) and least squares fitting of the XANES (31) have been detailed elsewhere. The results from fitting the spectra that are shown in Figure 9 indicate that $\mathrm{Fe}^{3+}$ partitions primarily with elements found in the hollandite phase (i.e. $\mathrm{Ba}, \mathrm{Ti}, \mathrm{Cs}$, and $\mathrm{Al}$ ), while $\mathrm{Fe}^{2+}$ partitions primarily with the $\mathrm{Nd}$-containing phase. Further analysis into the nature of the $\mathrm{Fe}^{2+}$-containing phase(s) is ongoing. However, the ionic radius of an eight-fold coordinated $\mathrm{Fe}^{2+}$ is likely too small to substitute for $\mathrm{Ca}^{2+}$ in zirconolite(32) and $\mathrm{Fe}^{2+}$ is not expected to readily substitute in simple perovskite structure $\left(\mathrm{ABO}_{3}\right)$ based on ionic radii considerations. However, $\mathrm{Fe}^{2+}$ may substitute on the A site in pyrochlore and as such, a complex pyrochlore phase with both $\mathrm{Nd}^{3+}$ and $\mathrm{Fe}^{2+}$ may be forming in addition to other reduced Fe titanate compounds.

\subsubsection{Phase Identification and Microstructure}

XRD confirmed three primary phases in the core samples as having hollandite, pyrochlore/zirconolite, and perovskite structures. Phase analysis conducted on the different morphologies observed in the individual cores indicated similar phase assemblage. In general, the XRD results indicated material in the CCIM was homogenous at varying depths in the melt as well as radially from the center to the edge of the melt. Phase abundances calculated from Rietveld refinement of the XRD patterns are summarized in Figure 10. In general, the relative phase abundances indicated the CCIM test was successful in producing a homogenous ceramic from a melt.

SEM backscattered electron (BSE) images of Zone 1 (dense), 2 (columnar), and 3 (porous) areas from Core D are shown in Figure 11 along with corresponding EDS elemental maps for zone 2. This set of BSE images and elemental maps are representative of all the core samples. In the BSE images, 3 to 5 distinct contrast phases are visually evident and no significant differences in elemental partitioning are evident in the maps, as expected, based on chemical composition and XRD analyses. Figure 11 also summarizes an averaged semi-quantitative elemental analysis that was performed for the various phases based on phases with similar chemical makeup but from several samples. Phases were identified based on the elements that measured greater than 1 atom \%. Notably, the hollandite phase contains $\mathrm{Al}$, which is known to readily substitute into hollandite structures and is used to stabilize pure Fe-hollandite ceramics.(12-13, 27) Hollandite is most distinctly identified in the $\mathrm{Ba}$ and $\mathrm{Ti}$ maps. Pyrochlore, zirconolite, and perovkite phases identified in XRD were less straightforward to identify using the SEM and EDS information. Specifically, $\mathrm{Ca}$ and $\mathrm{Zr}$ often appeared to coexist with lanthanide series elements in multiple phases making it impossible to distinguish zirconolite $\left(\mathrm{CaZrTi}_{2} \mathrm{O}_{7}\right)$, pyrochlore $\left(\mathrm{A}^{3+}{ }_{2} \mathrm{Ti}_{2} \mathrm{O}_{7}\right)$, and perovskite $\left(\mathrm{A}^{2+} \mathrm{TiO}_{3}\right)$ based on the composition data alone. These phases are most distinctly identified in the $\mathrm{Ca}, \mathrm{Zr}$, and $\mathrm{Nd}$ maps but it is also evident that significant elemental substitution exists in the samples making interpretation more complex.

The SEM/EDS data also revealed Fe-rich and Cs-rich phases in addition to the major phases. The Fe-rich phases appeared to contain $\mathrm{Al}$ and possibly minor amounts of $\mathrm{Ba}$. This result was not unexpected considering that various parasitic phases containing $\mathrm{Fe}, \mathrm{Al}$, or $\mathrm{Ba}$ have been observed in previous work.(27) Furthermore, because the ceramic in this test was formulated for a pure Fe-hollandite, excess $\mathrm{Fe}$ would be available from its replacement by $\mathrm{Al}$ (introduced during processing) in the hollandite phase 
to from parasitic compounds (and substitute in pyrochlore/zirconolite phases). Several Cs-rich phases have also been observed in previous work. In particular, non-durable Cs-Mo containing compounds and $\mathrm{Cs}-\mathrm{Al}$ titanates are known to form. Interestingly, Cs-Mo containing phases did not appear the dominant Cs-rich phase in the core samples. Instead, Cs appeared in combination with other elements, most markedly $\mathrm{Al}$ and possibly various lanthanides. As noted previously, the Fe-hollandite formulation does not represent an optimal waste form composition but was selected for this initial proof-of-principal testing due to its lower melting temperature behavior and compatibility with the current INL CCIM design.

TEM/STEM was performed on Core F Zone 1 to further investigate the chemistry and crystallinity of phases in the CCIM material. Figure 12 shows three sets TEM/STEM images, EDX spectra, and SAED patterns. Each TEM image was taken across multiple phases in order to investigate the boundary region and the beam was aligned with a different phase in each image. In all images, the phase boundary is relatively sharp with no clear secondary phases at the boundaries. In Figure 12 (A) the beam was aligned with the phase identified as hollandite based on chemical composition obtained from EDX and crystalline symmetry, identified as tetragonal, from the SAED pattern. In Figure 12 (B) the beam was aligned with the phase identified as perovskite based on chemical composition obtained from EDX and crystalline symmetry from SAED pattern. This phase is possibly a $(\mathrm{Nd}, \mathrm{Sr}, \mathrm{Ca})(\mathrm{Ti}, \mathrm{Fe}) \mathrm{O}_{3}$ solid solution with the perovskite structure, which possess a monoclinic cell in a three-tilt system. In Figure 12 (C) the beam was aligned with the phase identified as zirconolite based on chemical composition obtained from EDX and crystalline symmetry from SAED pattern. The $(\mathrm{Ca}, \mathrm{Nd}) \mathrm{Zr}(\mathrm{Ti}, \mathrm{Fe})_{2} \mathrm{O}_{7}$ zirconolite phase was pseudo-cubic and is similar to pyrochlore which is an anion deficient superstructure based on the fluorite structure $\left(\mathrm{MX}_{2}\right)$, and occurs as various polytypes including monoclinic and trigonal. The major differences between zirconolite and pyrochlore, are the coordination number of $\mathrm{Zr}$ and the pyrochlore is expanded (by $\sim 4 \%$ ) along the zirconolite $\mathrm{C}$ axis (the pyrochlore [001] axis) relative to zirconolite. In another words, pyrochlore can be thought of as an expanded zirconolite.

\subsubsection{Chemical Durability}

Chemical durability was performed to assess the relative durability of different areas from the CCIM material. Specifically, potential differences in durability throughout the bulk material were tested by sampling material from different Zones (similar to the chemical composition testing). The results of the aqueous durability testing are summarized in Figure 13. Fractional release $(F R)$ of elements not shown in Figure 13 were below detection $(<0.1 \mathrm{ppm})$ in the leachate. Similar to the composition data, the greatest standard error was observed in the Zone 3 and 5 samples suggesting that precise sampling in those areas is difficult or that those areas possess a greater degree of inhomogeneity. The $F R$ results indicate $\mathrm{Cs}$ and $\mathrm{Al}$ elemental releases were practically constant across all zones. The Te $F R$ exhibited comparatively more variation from each zone. In particular, Zone 1 (dense) exhibited a higher Te $F R$ compared to the other zones. Mo $F R$ exhibited the greatest variation than the other elements in each zone. Recalling the SEM/EDS results, Mo appeared distributed throughout the ceramic, but may not have been chemically or uniformly incorporated into the primary phases. It is known that water soluble $\mathrm{Cs}, \mathrm{Ca}$, and $\mathrm{Sr}$ molybdates can form in synrock-type materials and these compounds may be a possible explanation for the Cs and Mo release rates. However, the lack of correlation between Cs and Mo FR and the low release of $\mathrm{Sr}$ and $\mathrm{Ca}$ indicate further explanation is needed.

\section{Conclusions}

The first scaled proof of principle test for melt-processing multi-phase crystalline waste forms for a combined UNF waste stream (Cs/Sr, fission products) was completed using a CCIM. Characterization of material fabricated during the test indicated that the ceramic material exhibited a desirable phase assemblage consisting primarily of hollandite, zirconolite/pyrochlore, and perovskite phases. The hollandite phase exhibited relatively narrow substitution of other elements as evidenced by the XANES, EDS/EDX data. In particular, the primary cations (excluding Ti which is in all phases) $\mathrm{Ba}, \mathrm{Cs}$, and $\mathrm{Fe}$ 
(3+) were well confined to the hollandite phase as evidenced in the XANES and EDS spectra. Comparatively, pure zirconolite and perovskite $\left(\mathrm{A}^{+3}\right)$ were not found and are not believed to exist in any appreciable amount. The close correspondence among $\mathrm{Ca}, \mathrm{Zr}$, and $\mathrm{Nd}$ in the data suggest complex phase reactions among the zirconolite, pyrochlore, and perovskite phases. In the zirconolite structure, $\mathrm{Ca}^{2+}$ or $\mathrm{Zr}^{4+}$ can be substituted by $\mathrm{Nd}^{3+}$, with the former being preferred due to the smaller disparity in ionic radii for $\mathrm{Ca}^{2+}$ and $\mathrm{Nd}^{3+}$.(33) In the case of $\mathrm{Ca}^{2+}$ substitution by $\mathrm{Nd}^{3+}$, charge compensation can occur by either trivalent cation substitution at $\mathrm{Zr}^{4+} / \mathrm{Ti}^{4+}$ sites, or via metal vacancy formation at $\mathrm{Ca}^{2+} / \mathrm{Zr}^{4+}$ sites. (34) Furthermore, extensive $\mathrm{Nd}$ substitution into the zirconolite structure leads to partitioning into pyrochlore and/or perovskite phases. While more precise determinations of compound stoichiometry in the $\mathrm{Ca}-\mathrm{Nd}-\mathrm{Zr}$ areas of the melt-processed samples are on-going, it is possible that many of these regions have nominal compositions of $\mathrm{Ca}_{1-x} \mathrm{Zr}_{1-x} \mathrm{Nd}_{2 x} \mathrm{Ti}_{2} \mathrm{O}_{7}$, where partitioning into various doped perovskite and pyrochlore phases occurs at critical $\mathrm{Nd}$ concentrations.

7-day tests performed on multiple samples from the fabricated material resulted in measureable release for $\mathrm{Al}, \mathrm{Cs}, \mathrm{Mo}$, and Te species. The fractional release of these elements were on the order of $0.001-0.1$ of the starting concentration. Overall, the variability in the fractional release indicates chemical and microstructural homogeneity.

This CCIM test improves our understanding and the feasibility of using an induction melter to process a ceramic waste form from a melt. Specifically, canister to canister homogeneity (production consistency) would appear to be excellent and although complex, the crystallization of the phases and the resulting elemental partitioning produced an acceptably durable ceramic waste form that incorporated constituents from a combined UNF waste stream. This test substantiates the importance and practicality of using induction melters to fabricate crystalline ceramic waste forms.

List of Table Captions:

Table 1. Target and Measured Elemental Concentrations (wt\%) in CCIM Feed Material.

Table 2. Core sample dimensions

Table 3. Measured elemental concentrations (wt\%) in the bulk CCIM material not separated by a zone.

Table 4. Measured $\mathrm{Fe}^{2+}$ Fraction in Core $\mathrm{D}$

List of Figure Captions:

Figure 1. Images captured inside of CCIM crucible showing (A) the Ti ring on alumina supports, (B) batch material packed under the ring (additional batch material was packed over the ring), and (C) the melted batch material after cooling.

Figure 2. Digital image showing core sample locations from solidified material in the melter.

Figure 3. Core sample F as-received after re-assembly.

Figure 4. SEM phase contrast images that reveal microstructure differences along the length of the cores.

Figure 5. Plot of mean elemental concentrations and corresponding standard deviations from samples grouped according to morphology (Zone) type. 
Figure 6. Plots of elemental mean concentrations as a function of zone.

Figure 7. Plot of mean elemental concentrations and corresponding standard deviations from samples grouped according to radial distance. (D: center, E: $1 / 2$ radius, F: edge, B: $1 / 2$ radius)

Figure 8. XANES data (A) collected at different spots (B) with different Fe intensities. High Fe concentrations areas are indicated by red color.

Figure 9. 2-D XANES plots showing Ti, Nd, Ba, Cs, Al, Ca, and Fe elemental distribution in Core $\mathrm{D}$ Zone 2. Distribution of $\mathrm{Fe}^{2+}$ and $\mathrm{Fe}^{3+}$ is also shown. The bi-color $\mathrm{Fe}$ plot is a composite (not total) of the $\mathrm{Fe}^{2+}$ (green) and $\mathrm{Fe}^{3+}$ (red) plots. The intensity scale bar corresponds to all plots but the absolute counts varied depending on element.

Figure 10. Summary of primary phase abundances in core samples compared to estimated abundances based on feed composition and target phase assemblage.

Figure 11. 600X magnification EDS elemental maps for Core F Zone 2.

Figure 12. TEM images of phase boundaries with the beam aligned to (A) hollandite, (B) perovskite, and (C) zirconolite/pyrochlore phases. SAED patterns and EDX spectra correspond to the phase aligned with the beam (and in "white" text)

Figure 13. Fractional release for elements with measureable response after exposure to PCT. Individual samples are indicated with " $x$ " and corresponding standard error bars are drawn. 


\section{REFERENCES}

1. Crum, J. V.; Maio, V. C.; McCloy, J.; Scott, C.; Riley, B.; Benefiel, B.; Vienna, J. D.; Archibald, K.; Rodriguez, C. P.; Rutledge, V.; Zhu, Z.; Ryan, J. V.; Olszta, M., J. Nucl. Mater. 444 (2014) 481-492.

2. $\quad$ Crum, J. V.; Turo, L.; Riley, B.; Tang, M.; Kossoy, A., J. Am. Ceram. Soc. 95 (2012) 1297-1303.

3. Donald, I. W., Properties of Radioactive Wasteforms. John Wiley \& Sons: Great Britain, 2010.

4. $\quad$ Ewing, R. C.; Lutze, W., Ceramics International 17 (1990) 287-293.

5. Jostsons, A. Synroc - progress and future prospects; The Fourth Conference on Nuclear Science and Engineering Australia, 2001; p 198.

6. Lutze, W.; Ewing, R. C., Sumamry and Evaluation of Nuclear Waste Forms. In Radioactive Waste Forms for the Future, Lutze, W.; Ewing, R. C., Eds. North Holland: Amsterdam, 1988; pp 699-740.

7. Ringwood, A. E.; Kesson, S. E.; Ware, N. G.; Hibberson, W.; Major, A., Nature 278 (5701) (1979) 219-223.

8. $\quad$ Gunn, D. S. D.; Allan, N. L.; Foxhall, H.; Harding, J. H.; Purton, J. A.; Smith, W.; Stein, M. J.; Todorov, I. T.; Travis, K. P., J. Mater. Chem. 22 (11) (2012) 4675-4680.

9. $\quad$ Ubic, R.; Reaney, I. M.; Lee, W. E., J. Mater. Res. 14 (04) (1999) 1576-1580.

10. Xu, H. F.; Wang, Y. F., J. Nucl. Mater. 279 (1) (2000) 100-106.

11. Aubin-Chevaldonnet, V.; Caurant, D.; Dannoux, A.; Gourier, D.; Charpentier, T.; Mazerolles, L.; Advocat, T., J. Nucl. Mater. 366 (1-2) (2007) 137-160.

12. Carter, M. L.; Vance, E. R.; Li, H., Mat. Res. Soc. Symp. Proc. 807 (2003) 249-254.

13. Carter, M. L.; Vance, E. R.; Mitchell, D. R. G.; Zhang, Z., Mat. Res. Soc. Symp. Proc. 824 (2004) 249-254.

14. Knyazev, O. A.; Nikonov, B. S.; Omelianenko, B. I.; Stefanovskii, S. V.; Yudintsev, S. V.; Day, R.; Vance, E. R., Proceedings of the International Topical Meeting on Nuclear and Hazard Waste Management (Spectrum '96) (1996) 2130-2137.

15. Sobolev, I. A.; Stefanovskii, S. V.; Ioudintsev, S. V.; Nikonov, B. S.; Omelianenko, B. I.; Mokhov, A. V., Mat. Res. Soc. Symp. Proc. 465 (1997) 363-370.

16. Sobolev, I. A.; Stefanovskii, S. V.; Omelianenko, B. I.; Ioudintsev, S. V.; Vance, E. R.; Jostons, A., Mat. Res. Soc. Symp. Proc. 465 (1997) 371-378.

17. Amoroso, J.; Marra, J. C.; Tang, M.; Lin, Y.; Chen, F.; Su, D.; Brinkman, K. S., J. Nucl. Mater. 454 (1-3) (2014) 12-21.

18. Demine, A. I.; Krylova, N. V.; Poluektov, P. P.; Shestoperov, I. N.; Smelova, T. N.; Gorn, V. F.; Medvedev, G. M., Mater. Res. Soc. Symp. Proc. 663 (2001) 27-34.

19. Stefanovsky, S. V.; Ptashkin, A. G.; Knyazev, O. A.; Dmitriev, S. A.; Yudintsev, S. V.; Nikonov, B. S., J. Alloys Compd. 444 (2007) 438-442.

20. Baumann, E. W. Colorimetric Determination of Ferrous-Ferric Ratio in Glass; US Department of Energy Report DPST-87-304; Savannah River Laboratory: Aiken, 1987.

21. Jantzen, C. M.; Bibler, N. E.; Beam, D. C.; Crawford, C. L.; Pickett, M. A. Characterization of the Defense Waste Processing Facility (DWPF) Environmental Assessment (EA) Glass Standard Reference Material; U.S. Department of Energy Report WSRC-TR-92-346 Rev. 1; Westinghouse Savannah River Company: Aiken, SC, 1993.

22. ASTM Standard C1285-14, "Standard Test Methods for Determining Chemical Durability of Nuclear, Hazardous, and Mixed Waste Glasses and Multiphase Glass Ceramics: The Product Consistency Test (PCT)," ASTM International, West Conshohocken, PA, 2014.

23. Lide, D. R., CRC Handbook of Chemistry and Physics. 77th (Student) ed.; CRC Press: Boca Raton, FL, 1996.

24. Ahmed, M. A. K.; Fjellvag, H.; Kjekshus, A., J. Chem. Soc. Dalton Trans. (2000) 4542-4595. 
25. Ropp, R. C., Encyclopedia of the Alkaline Earth Compounds. Elsevier Science: UK, 2012.

26. Tumurugoti, P.; Sundaram, S. K.; Misture, S. T.; Marra, J. C.; Amoroso, J. W., J. Nucl. Mater. 473 (2016) 178-188.

27. Amoroso, J.; Marra, J.; Conradson, S. D.; Tang, M.; Brinkman, K., J. Alloys Compd. 584 (2014) 590-99.

28. Brinkman, K.; Amoroso, J.; Marra, J.; Tang, M. Crystalline Ceramic Waste Forms: Comparison of Reference Process for Ceramic Waste Form Fabrication; US Department of Energy Report SRNL-STI-2013-00442 (FCRD-SWF-2013-000229); Savannah River National Laboratory: Aiken SC, 2013.

29. Mayhew, L. E.; Webb, S. M.; Templeton, A. S., Environ. Sci. Technol. 45 (2011) 4468-4474.

30. Webb, S. M., Amer. Inst. Phys. Conf. Proc. 1365 (2011) 196-199.

31. Webb, S. M., Physica Scripta 2005 (T115) (2005) 1011.

32. Lumpkin, G. R.; Begg, B. D.; Smith, K. L., Radiation Damage Effects in Pyrochlore and Zirconolite Ceramic Matrices for the Immobilization of Actinide-rich Wastes. In Proceedins of the International Conference on Scientific Research on the Back-end of the Fuel Cycle for the $21^{\text {st }}$ Century, France, 2000.

33. Jafar, M.; Sengupta, P.; Achary, S. N.; Tyagi, A. K., J. Am. Ceram. Soc. 97 (2014) 609-616.

34. Coelho, A. A.; Cheary, R. W.; Smith, K. L., J. Solid State Chem. 129 (1997) 346-359. 
Table 1:

\begin{tabular}{|l|r|r|}
\hline & Target & Measured \\
\hline Ba & 10.69 & 10.25 \\
\hline Ca & 0.93 & 0.91 \\
\hline Cd & 0.09 & 0.04 \\
\hline Ce & 2.48 & 2.43 \\
\hline Cs & 2.54 & 2.19 \\
\hline Eu & 0.14 & 0.17 \\
\hline Fe & 10.00 & 9.76 \\
\hline Gd & 0.13 & 0.13 \\
\hline La & 1.26 & 1.17 \\
\hline Mo & 0.53 & 0.37 \\
\hline Nd & 4.19 & 3.74 \\
\hline Pr & 1.16 & 1.18 \\
\hline Rb & 0.36 & $n . m$. \\
\hline Se & 0.05 & $<0.10$ \\
\hline Sm & 0.87 & 0.90 \\
\hline Sn & 0.05 & 0.09 \\
\hline Sr & 0.78 & 1.01 \\
\hline Te & 0.49 & 0.55 \\
\hline Ti & 27.55 & 27.15 \\
\hline Y & 0.46 & 0.44 \\
\hline Zr & 2.07 & 1.98 \\
\hline & & \\
\hline Sum & 66.8 & 64.5 \\
\hline
\end{tabular}

\begin{tabular}{|c|c|c|}
\hline $\begin{array}{c}\text { Batch } \\
\text { Chemical }\end{array}$ & Target & Calculated $^{\mathrm{e}}$ \\
\hline $\mathrm{BaCO}_{3}$ & 15.36 & 14.72 \\
\hline $\mathrm{CaCO}_{3}$ & 2.31 & 2.28 \\
\hline CdO & 0.10 & 0.05 \\
\hline $\mathrm{CeO}_{2}$ & 3.05 & 2.98 \\
\hline $\mathrm{Cs}_{2} \mathrm{CO}_{3}$ & 3.11 & 2.69 \\
\hline $\mathrm{Eu}_{2} \mathrm{O}_{3}$ & 0.16 & 0.19 \\
\hline $\mathrm{Fe}_{2} \mathrm{O}_{3}$ & 14.29 & 13.95 \\
\hline $\mathbf{G d}_{2} \mathrm{O}_{3}$ & 0.15 & 0.15 \\
\hline $\mathrm{La}_{2} \mathrm{O}_{3}$ & 1.48 & 1.37 \\
\hline $\mathrm{MoO}_{3}$ & 0.53 & 0.56 \\
\hline $\mathrm{Nd}_{2} \mathrm{O}_{3}$ & 4.89 & 4.37 \\
\hline $\mathbf{P r}_{6} \mathbf{O}_{11}$ & 1.40 & 1.43 \\
\hline $\mathrm{Rb}_{2} \mathrm{CO}_{3}$ & 0.49 & n.m. \\
\hline $\mathrm{SeO}_{2}$ & 0.08 & $<0.14$ \\
\hline $\mathrm{Sm}_{2} \mathrm{O}_{3}$ & 1.01 & 1.04 \\
\hline $\mathrm{SnO}_{2}$ & 0.07 & 0.11 \\
\hline $\mathrm{SrCO}_{3}$ & 1.31 & 1.70 \\
\hline $\mathrm{TeO}_{2}$ & 0.61 & 0.69 \\
\hline $\mathrm{TiO}_{2}$ & 45.96 & 45.31 \\
\hline $\mathbf{Y}_{2} \mathbf{O}_{3}$ & 0.59 & 0.56 \\
\hline $\mathrm{ZrO}_{2}$ & 2.79 & 2.68 \\
\hline Total & 100.0 & 96.8 \\
\hline
\end{tabular}

e Values are based on conversion of measured elementals to batch components.

${ }^{\mathrm{f}}$ Measured and calculated values do not include Rb contribution. 
Table 2:

\begin{tabular}{|c|c|}
\hline Core & $\begin{array}{c}\text { Core Depth } \\
\text { (in) }\end{array}$ \\
\hline A & $1 \frac{3}{8}$ \\
\hline B & $1 \frac{1}{2}$ \\
\hline C & $11 \frac{16}{13 / 8}$ \\
\hline D & 13 \\
\hline E & 2 \\
\hline F & $15 / 8$ \\
\hline G & $1 \frac{1}{4}$ \\
\hline
\end{tabular}


Table 3:

\begin{tabular}{||c|c|r|}
\hline Element & Target & Measured \\
\hline Al & 0.00 & 2.21 \\
\hline Ba & 10.69 & 10.54 \\
\hline Ca & 0.93 & 0.93 \\
\hline Cd & 0.09 & $<0.10$ \\
\hline Ce & 2.48 & 2.47 \\
\hline Cs & 2.54 & 1.73 \\
\hline Eu & 0.14 & 0.12 \\
\hline Fe & 10.00 & 9.88 \\
\hline Gd & 0.13 & 0.12 \\
\hline La & 1.26 & 1.22 \\
\hline Mo & 0.53 & 0.15 \\
\hline Nd & 4.19 & 4.02 \\
\hline Pr & 1.16 & 1.21 \\
\hline Rb & 0.36 & $n . m$. \\
\hline Se & 0.05 & $<0.10$ \\
\hline Zr & 2.07 & 1.97 \\
\hline Sm & 0.87 & 0.85 \\
\hline Sn & 0.05 & $n . m$. \\
\hline Sr & 0.78 & 0.99 \\
\hline Te & 0.49 & 0.13 \\
\hline Ti & 27.55 & 30.13 \\
\hline Y & 0.46 & 0.40 \\
\hline
\end{tabular}


Table 4:

\begin{tabular}{|c|c|}
\hline & $\mathbf{F e}^{2+} / \mathbf{F e}$ Total \\
\hline Zone 1 & 0.13 \\
\hline Zone 2 & 0.19 \\
\hline Zone 5 & 0.20 \\
\hline Zone 4 & 0.24 \\
\hline
\end{tabular}




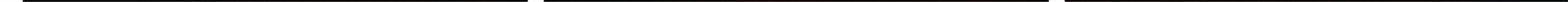

(C) 


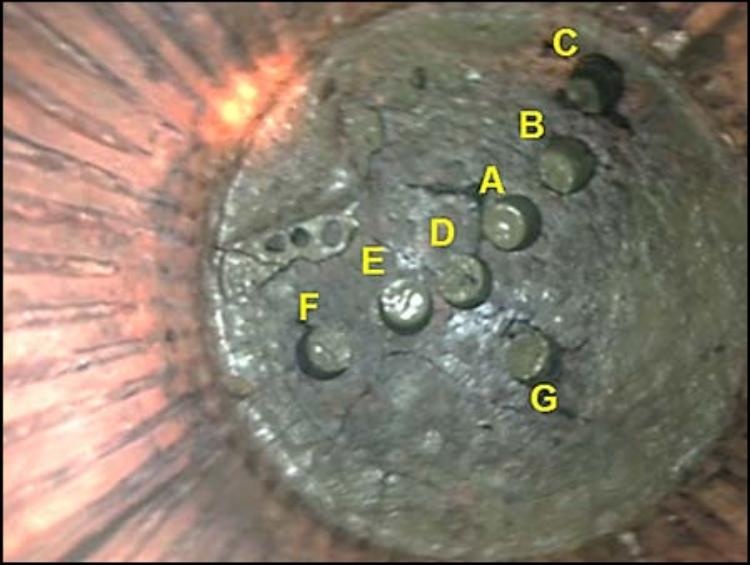




\section{$15 / 8^{\prime \prime}$}




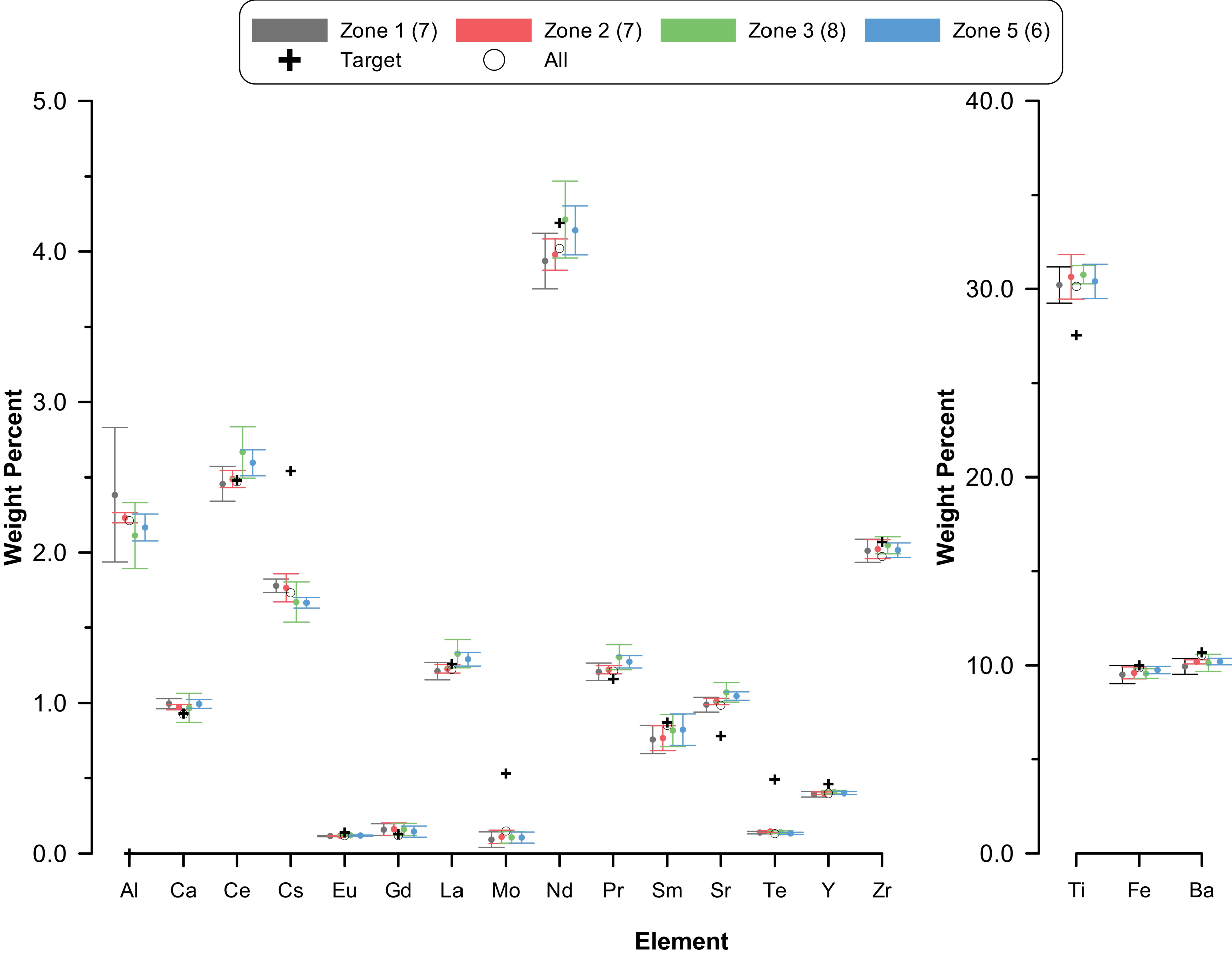




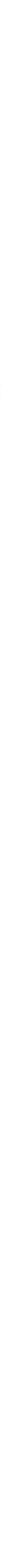




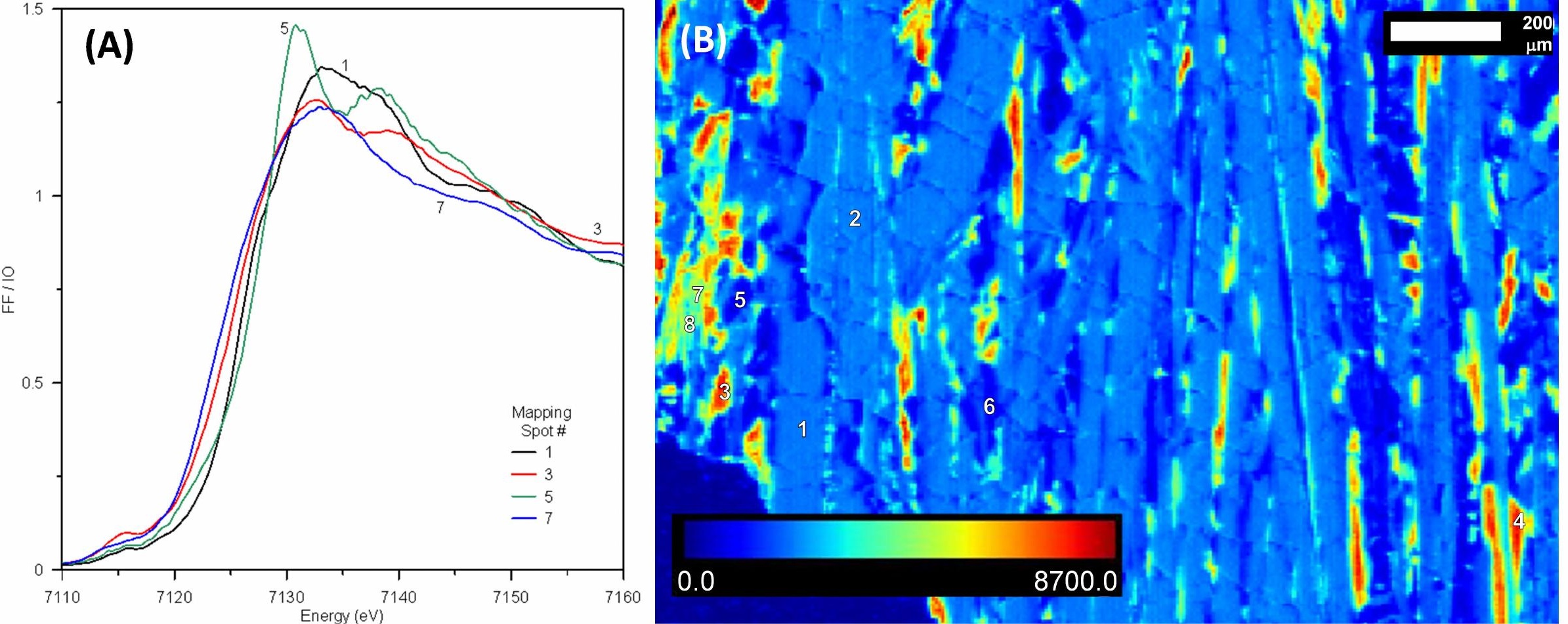




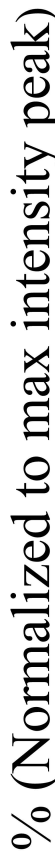

Zone 1 (Dense) Zone 2 (Columnar) Zone 3 (Porous)

60

80

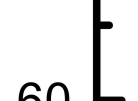

40

20
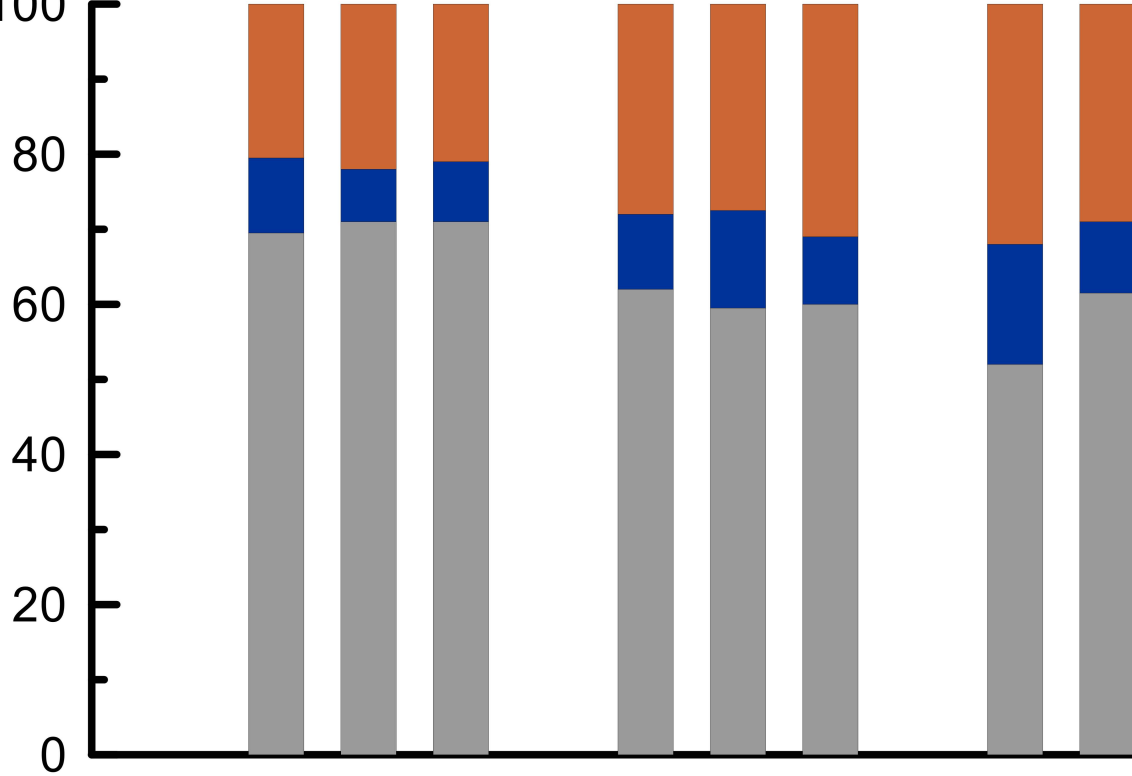

\section{E F}

D E F

D E F

$($ Bottom $\leftarrow)$ Core $(\rightarrow$ Top $)$ 

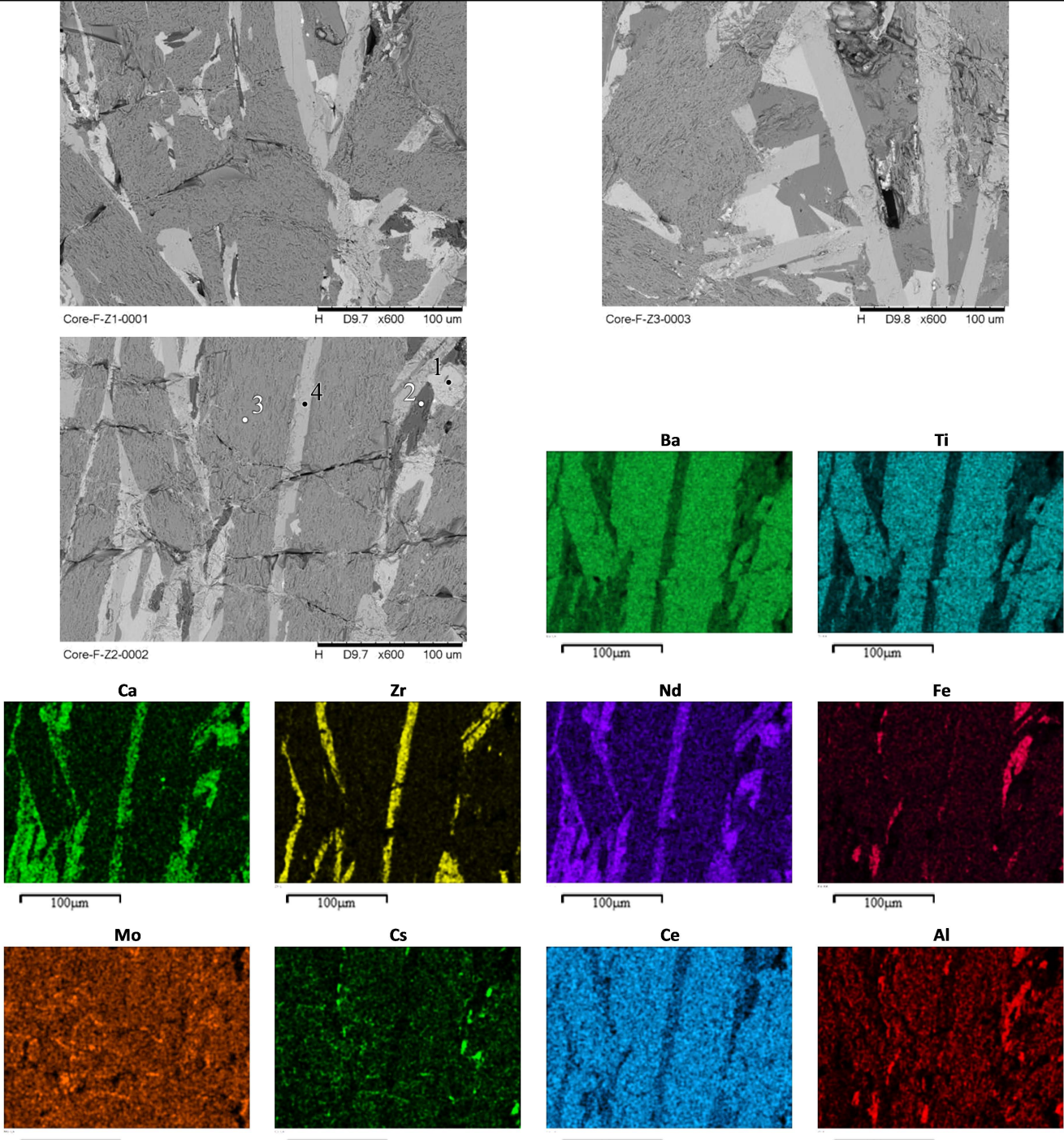

$100 \mu \mathrm{m}$

$100 \mu \mathrm{m}$

$100 \mu \mathrm{m}$

$100 \mu \mathrm{m}$

Spot 1

Spot 2

Spot 3

Spot 4
$(\mathrm{Al}, \mathrm{Nd}, \mathrm{Ce})_{\mathrm{x}}(\mathrm{Ca}, \mathrm{Sr})_{\mathrm{y}} \mathrm{Ti}_{1.2} \mathrm{O}_{3.0}$ (perovskite)

$(\mathrm{AlFe})_{1.70} \mathrm{Ti}_{1.28} \mathrm{O}_{5.0}\left(\mathrm{FeAlTiO}_{5}\right)$

$\mathrm{Ba}_{0.31} \mathrm{Cs}_{0.19} \mathrm{Fe}_{1.2} \mathrm{Al}_{0.76} \mathrm{Ti}_{6.4} \mathrm{O}_{16}$ (hollandite)

$(\mathrm{Zr}, \mathrm{Fe}, \mathrm{Nd}, \mathrm{Ca}, \mathrm{Al}, \mathrm{Ce})_{1.7} \mathrm{Ti}_{2.0} \mathrm{O}_{7.0}$ (pyrochlore/zirconolite) 


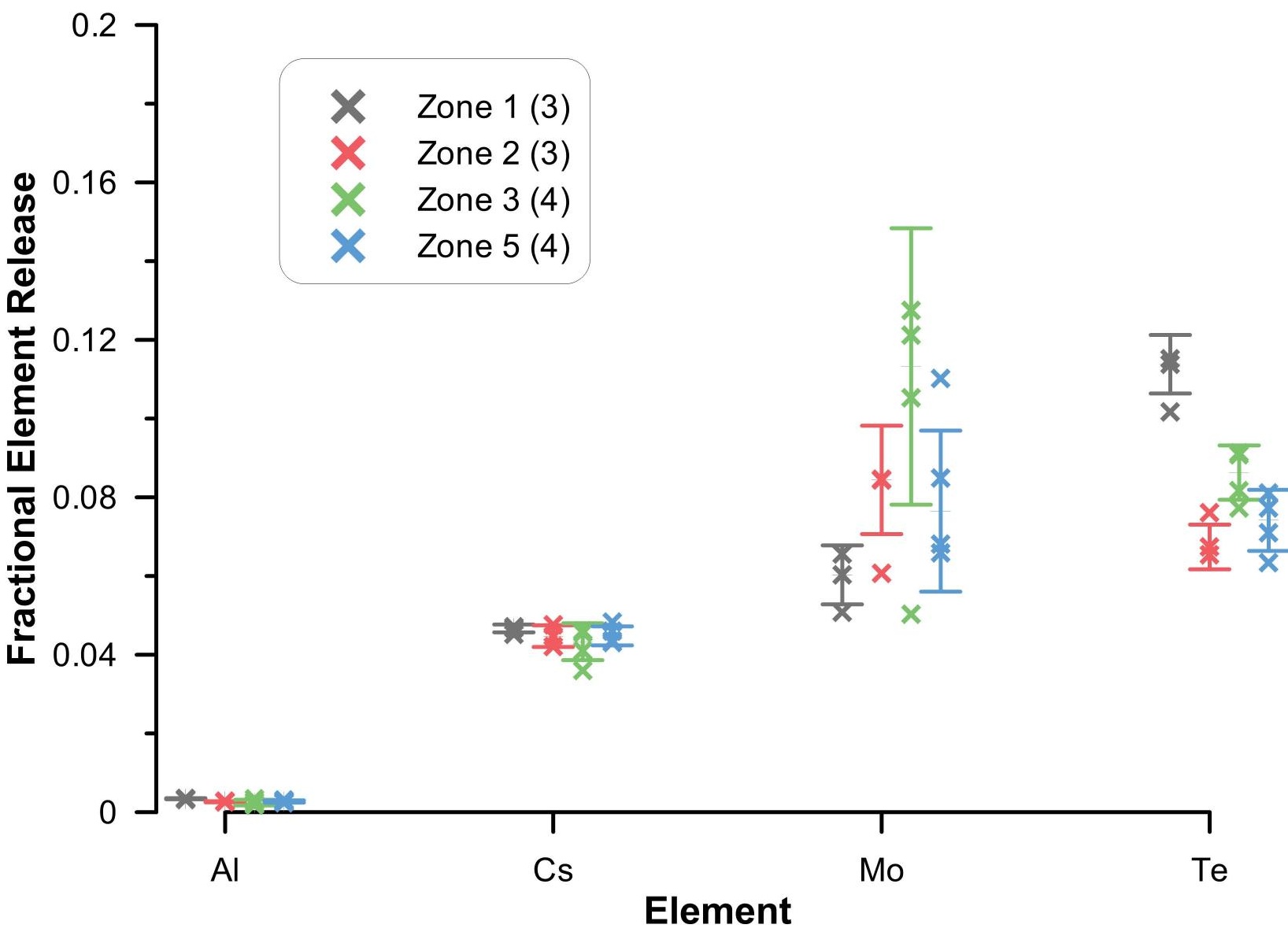

